\title{
Asymmetric septal hypertrophy in patients with severe aortic stenosis: The usefulness of associated septal myectomy
}

\author{
Luigi Di Tommaso, MD, Paolo Stassano, MD, Vito Mannacio, MD, Veronica Russolillo, MD, \\ Mario Monaco, MD, Giovanni Pinna, MD, and Carlo Vosa, MD
}

\begin{abstract}
Objective: Asymmetric septal hypertrophy frequently coexists with severe aortic stenosis and can be unmasked after successful aortic valve replacement (AVR), jeopardizing the clinical and echocardiographic results. The aim of our study was to investigate, at 5 years postoperatively, the effectiveness of myectomy associated with AVR on left ventricular (LV) mass regression and LV diastolic function.
\end{abstract}

\begin{abstract}
Methods: From 1997 and 2004, 86 patients with a diagnosis of severe aortic stenosis and asymmetric septal hypertrophy consecutively underwent AVR (group A) or AVR and concomitant myectomy (group B). To assess the improvement in LV mass and LV diastolic function, we studied the 52 survivors ( 23 in group A and 29 in group B) who had the same prosthesis type (beleaflet mechanical), the same size $(21 \mathrm{~mm})$, and the same follow-up length.

Results: In group A, the LV mass index regressed from $119.2 \pm 22.0$ to $113.8 \pm 21.8$, and in group B, it regressed from $121.6 \pm 20.8$ to $112.7 \pm 20.0(P<.0005)$. In group $\mathrm{A}$, the $\mathrm{E} / \mathrm{E}^{\prime}$ ratio improved from $15.3 \pm 3.0$ to $11.8 \pm 3.0$, and in group $\mathrm{B}$, it improved from $16.2 \pm 3.2$ to $12.1 \pm 3.3(P=.02)$.

Conclusions: Surgeons should inspect the LV outflow tract at AVR. Concomitant myectomy at AVR is a safe and effective procedure that improves LV mass regression and LV diastolic function. (J Thorac Cardiovasc Surg 2013;145:171-5)
\end{abstract}

In aortic stenosis (AS), left ventricular (LV) hypertrophy is an adaptive process that compensates for ventricle pressure overload. This process is accompanied by a remodeling of the left ventricle that involves the muscular and nonmuscular compartments of the ventricle with muscle hypertrophy and abnormalities of the collagen network. ${ }^{1}$ Usually this degree or type of LV remodeling is uniform and symmetric; however, sometimes an area of the left ventricle shows a nonuniform pattern of hypertrophy in which 1 portion of the ventricle-usually the septum - shows a greater degree of thickening than other areas. ${ }^{2}$ This type of hypertrophy in the setting of valvular AS is not uncommon and can be easily overlooked at aortic valve replacement (AVR).

After AVR, the persistence of this degree of asymmetric LV hypertrophy with an intraventricular gradient can lead to less than optimal early and late postoperative results, including a lack of abolition of gradient into the LV outflow tract, a lack of regression of the LV mass (LVM), diastolic dysfunction and, sometimes, persistence of symptoms. ${ }^{3,4}$

\footnotetext{
From the Division of Cardiac Surgery, University Federico II Medical School, Naples, Italy.

Disclosures: Authors have nothing to disclose with regard to commercial support.

Luigi Di Tommaso and Paolo Strassano have contributed equally to this article.

Received for publication May 19, 2011; revisions received Aug 25, 2011; accepted

for publication Oct 31, 2011; available ahead of print Feb 17, 2012.

Address for reprints: Luigi Di Tommaso, MD, Division of Cardiac Surgery, University Federico II Medical School, Via Gemito, Caserta 81100 Italy (E-mail: lditommaso@tin.it).

0022-5223/\$36.00

Copyright (c) 2013 by The American Association for Thoracic Surgery

doi:10.1016/j.jtcvs.2011.10.096
}

In this situation, the operative approach is not uniform and not many studies that can help in the decision-making process are available. Most surgeons perform only AVR, on the assumption that, by reducing the LV afterload with the valve replacement, it induces a trend toward the normalization of LV hemodynamics. However, others have recommended a more liberal use of septal myectomy at AVR. ${ }^{5}$

Doppler tissue imaging (DTI) is an ultrasound modality that, through measurements of the systolic and diastolic velocities within the myocardium and at the corners of the mitral annulus, reflects the shortening and lengthening of the myocardial fibers along a longitudinal plane, thus allowing a precise estimate of diastolic function. ${ }^{6}$

To precisely assess the value and safety of associated septal myectomy at AVR and the improvements in LVM and diastolic function, we retrospectively compared 2 groups of patients with the same preoperative asymmetric septal thickness who underwent surgery by the same surgical group in 2 different periods: 1 group underwent only AVR and 1 group underwent septal myectomy in association with AVR.

\footnotetext{
METHODS

The retrospective nature of the study induced us to adopt strict criteria for patient enrollment to achieve meaningful results. From January 1997 to December 2004, 591 consecutive patients with a diagnosis of severe AS underwent AVR at our institution. Of these patients, $86(14 \%)$ had asymmetric septal hypertrophy. From January 2000 onward, we added septal myectomy to AVR for these patients. Thus, 34 patients underwent AVR only (group A, from January 1997 to December 1999) and 52 patients underwent AVR plus septal myectomy (group B, from January 2000 to
} 


\section{Abbreviations and Acronyms \\ AS $=$ aortic stenosis \\ $\mathrm{AVR}=$ aortic valve replacement \\ DTI $=$ Doppler tissue imaging \\ $\mathrm{LV}=$ left ventricular}

December 2004). Because the valve annulus and the size and type of the prosthesis implanted can influence the behavior of the left ventricle at late follow-up, ${ }^{7}$ from the 86 patients, we identified those patients with the same prosthesis type and size and same follow-up length. We selected the St Jude and Carbomedics mechanical valves, which are the preferred mechanical valves at our center, ${ }^{8}$ and we selected a prosthesis size of 21 $\mathrm{mm}$, which is the size we mostly use for severe AS. Therefore, we compared $23(67.6 \%)$ of 34 patients who underwent AVR (group A) and 29 $(55.7 \%)$ of 52 patients who underwent associated myectomy at AVR (group B), who had the same follow-up length of 5 years.

For the purposes of the present study, asymmetric septal hypertrophy was echocardiographically defined as a disproportional thickness of the interventricular septum compared with the LV posterior wall. The septal/posterior wall thickness ratio was set at 1.3 or greater $^{2,9}$ (range, 13 to $17 \mathrm{~mm}$ ). Severe AS was defined as a mean aortic gradient greater than $40 \mathrm{~mm} \mathrm{Hg}$, aortic valve area less than $1.0 \mathrm{~cm}^{2}$, and a jet velocity greater than $4 \mathrm{~m} / \mathrm{s} .{ }^{10}$

We carefully excluded patients with the diagnosis of hypertrophic cardiomyopathy or dynamic outflow tract obstruction with systolic anterior motion of the mitral valve and those who had septal hypertrophy in the setting of less than severe AS. Finally, to avoid any bias owing to the role of the mitral valve on the outflow tract of the left ventricle, we also excluded patients undergoing concomitant procedures on the mitral valve.

Patients with concomitant coronary artery bypass grafting were included, because at our center, they constitute a large fraction of those undergoing AVR. ${ }^{8}$

The institutional research ethics committee approved the present study, and all patients provided written informed consent.

\section{Preoperative and Postoperative Evaluations}

The diagnosis of severe AS was confirmed preoperatively by transthoracic echocardiography within 2 weeks of surgery. All patients also underwent an echocardiographic study (transesophageal) intraoperatively and before hospital discharge (transthoracic). At 5 years of follow-up, echocardiography was performed by echocardiographers who were unaware of the treatment received. Conventional Doppler echocardiographic and DTI data were obtained from all surviving patients. Two-dimensional and Doppler echocardiographic studies were performed with a commercially available echocardiography unit, equipped with an imaging transducer having pulsed wave and DTI capability. All Doppler echocardiographic examinations and DTI recordings were measured during normal respiration. Standard parasternal, apical, subcostal, and suprasternal views were obtained. The LV diameter and thickness were measured using M-mode echocardiography. The LVM was calculated using the Penn formula described by Devereux and Reichek. ${ }^{11}$ The LVM was indexed by dividing the LVM (in grams) by the body surface area. Continuous-wave, pulsed-wave, and color Doppler studies were made to assess the peak transvalvular gradient, mean transvalvular gradient, and effective orifice area of the aortic valve, respectively. The peak and mean gradients were calculated using the modified Bernoulli equation. The effective orifice area was calculated using the simplified continuity equation and indexed by the body surface area. From the apical window, the pulsed Doppler sample volume was placed at the mitral valve tips, and 5 to 10 cardiac cycles were recorded. For DTI, the filter setting was lowered, and the Nyquist limit was adjusted to a range of 15 to $20 \mathrm{~cm} / \mathrm{s}$. Gain was minimized to allow for a clear tissue signal with minimal background noise. The $\mathrm{E}^{\prime}$ wave was measured from the apical 4-chamber view, with a 2- to 5-mm sample volume placed at the septal corner of the mitral annulus. The measurements were recorded with simultaneous electrocardiography at a sweep speed of 50 to $100 \mathrm{~mm} / \mathrm{s}$. The measurements were made in 3 to 5 cardiac cycles and averaged.

\section{Operative Technique}

Throughout the study period, the surgical and myocardial protection procedures did not change. In both groups, AVR was undertaken through a median sternotomy, with standard cardiopulmonary bypass under mild hypothermia $\left(32^{\circ} \mathrm{C}\right)$ and cold blood cardioplegia. After removal of the usually calcified aortic valves, the prostheses were implanted with interrupted horizontal mattress sutures with pledgeted 2-0 nonabsorbable braided polyester. In group B, after the removal of the aortic valve and before implanting the prosthesis, concomitant septal myectomy was performed. The myectomy included resection of septal muscle from the nadir of the right aortic sinus to the commissure between the left and right cusps, just as in septal myectomy for hypertrophic obstructive cardiomyopathy. Of course, septal myectomy in these patients was limited compared with what we usually perform for true hypertrophic obstructive cardiomyopathy.

Postoperatively, patients received lifelong warfarin anticoagulation, with an international normalized ratio target of 2.0 to 2.5 . $^{8}$

The patients were annually seen by a cardiac surgeon of our team. Missing information was completed with the patient's physician and/or the patient's family.

\section{Statistical Analysis}

Statistical analyses were performed using the Statistical Package for Social Sciences, version 13.01, for Windows (SPSS, Chicago, Ill). Data are expressed as the mean value \pm standard deviation for continuous variables and as numbers and percentages for categorical variables. The preoperative and postoperative measurements were compared using Student's paired $t$ test. The chi-square test or Fisher's exact test (for sparse data) was used to compare the categorical variables and to assess statistical significance between the 2 groups. The 5-year follow-up period for each patient was calculated from the date of operation to the fifth year of follow-up contact with a surgeon of our team.

\section{RESULTS}

The clinical characteristics and preoperative echocardiographic measurements of the 52 surviving patients (23 in group A and 29 in group B) are listed in Tables 1 and 2, respectively. The 2 groups were homogeneous regarding the demographic, clinical, and echocardiographic data. Specifically, no differences were found in preoperative aortic valve area or the peak or mean gradients. Most patients had a calcific stenosis of either a tricuspid or bicuspid aortic valve. A total of 16 patients, 8 in each group, underwent associated coronary artery bypass grafting. No patient developed permanent atrioventricular block or septal perforation. Transient postoperative atrial fibrillation developed in 19 patients $(36.5 \%)$ that had reverted to sinus rhythm before hospital discharge.

No structural or functional prosthesis abnormality was found in either group.

\section{LVM and Geometry}

$\mathrm{LV}$ remodeling due to the severe AS was documented by an increased LVM, LVM index, and interventricular 
TABLE 1. Preoperative and operative data

\begin{tabular}{|c|c|c|c|}
\hline Variable & $\begin{array}{l}\text { Group A } \\
(\mathbf{n}=\mathbf{2 3})\end{array}$ & $\begin{array}{l}\text { Group B } \\
(\mathbf{n}=29)\end{array}$ & $\begin{array}{r}P \\
\text { valu }\end{array}$ \\
\hline Age $(y)$ & $61.9 \pm 7.9$ & $62.5 \pm 8.1$ & .9 \\
\hline Women & $14(60.9)$ & $17(58.6)$ & .8 \\
\hline Body surface area $\left(\mathrm{m}^{2}\right)$ & $1.76 \pm 0.13$ & $1.73 \pm 0.12$ & .4 \\
\hline \multicolumn{4}{|l|}{ Etiology } \\
\hline Rheumatic & $6(26.1)$ & $9(31.0)$ & .9 \\
\hline Bicuspid aorta & $3(13.0)$ & $2(6.9)$ & .2 \\
\hline Degenerative & $14(60.9)$ & $18(62.1)$ & .9 \\
\hline Hypertension & $14(60.9)$ & $17(58.6)$ & .9 \\
\hline Myocardial revascularization & $8(34.8)$ & $8(27.6)$ & .8 \\
\hline $\begin{array}{l}\text { Chronic obstructive pulmonary } \\
\text { disease }\end{array}$ & $1(4.3)$ & $1(3.4)$ & .7 \\
\hline Diabetes mellitus & $4(17.4)$ & $6(20.7)$ & .5 \\
\hline Chronic renal insufficiency & $2(8.7)$ & $4(13.8)$ & .4 \\
\hline Cerebrovascular accident & $4(17.4)$ & $5(17.2)$ & 6 \\
\hline Peripheral vascular disease & $1(4.3)$ & $2(6.9)$ & 6 \\
\hline \multicolumn{4}{|l|}{ Symptoms } \\
\hline Syncope & $3(13.0)$ & $7(24.1)$ & .2 \\
\hline Angina & $9(39.1)$ & $14(48.3)$ & .7 \\
\hline Dyspnea & $13(56.5)$ & $13(44.8)$ & .5 \\
\hline Asymptomatic & $5(21.7)$ & $6(20.7)$ & .8 \\
\hline NYHA class III-IV & $12(52.2)$ & $15(51.7)$ & .8 \\
\hline CCS class III-IV & $12(52.2)$ & $14(48.3)$ & .8 \\
\hline Aortic valve area $\left(\mathrm{cm}^{2}\right)$ & $0.74 \pm 0.06$ & $0.76 \pm 0.04$ & .1 \\
\hline Peak gradient $(\mathrm{mm})$ & $84.2 \pm 17.1$ & $87.1 \pm 16.3$ & .5 \\
\hline Mean gradient $(\mathrm{mm})$ & $61.2 \pm 17.6$ & $66.9 \pm 16.6$ & .2 \\
\hline Cardiopulmonary bypass (min) & $87.2 \pm 47.3$ & $91.7 \pm 51.5$ & .7 \\
\hline Aortic crossclamp duration (min) & $68.8 \pm 22.1$ & $72.1 \pm 19.9$ & .7 \\
\hline
\end{tabular}

Data presented as mean \pm standard deviation or numbers, with percentages in parentheses. NYHA, New York Heart Association (functional classification); CCS, Canadian Cardiovascular Society (classification).

septum thickness preoperatively (Table 2). Both these values decreased in groups A and B at 5 years of followup (Table 2). Patients with added myectomy (group B) had a more favorable reduction in the LVM, LVM index, and interventricular septum thickness than the patients with AVR alone (group A). The LVM decreased from $207.6 \pm 30.1 \mathrm{~g}$ to $198.3 \pm 30.5 \mathrm{~g}$ in group $\mathrm{A}$ and from $208.3 \pm 28.9 \mathrm{~g}$ to $193.2 \pm 28.7 \mathrm{~g}$ in group $\mathrm{B}$, with a regression ratio of $4.6 \pm 1.8$ and $7.3 \pm 3.7$, respectively $(P=.002)$.

The LVM index decreased from $119.2 \pm 22.0 \mathrm{~g} / \mathrm{m}^{2}$ to $113.8 \pm 21.8 \mathrm{~g} / \mathrm{m}^{2}$ in group A and from $121.6 \pm 20.8$ $\mathrm{g} / \mathrm{m}^{2}$ to $112.7 \pm 20.0 \mathrm{~g} / \mathrm{m}^{2}$ in group $B$, with a regression ratio of $4.6 \pm 1.8$ in group $\mathrm{A}$ and $7.3 \pm 3.7$ in group $\mathrm{B}$ $(P=.002$; Table 2$)$.

\section{Diastolic Function}

The $\mathrm{E} / \mathrm{E}^{\prime}$ ratio measurement had decreased at 5 years postoperatively in both groups, but group B patients had a more pronounced improvement in diastolic function than did group A patients. The $\mathrm{E} / \mathrm{E}^{\prime}$ ratio decreased from $15.3 \pm 3.0$ to $11.8 \pm 3.0$ in group $\mathrm{A}$ and from $16.2 \pm 3.2$
TABLE 2. Changes in LV function

\begin{tabular}{|c|c|c|c|}
\hline Variable & $\begin{array}{c}\text { Group A } \\
(\mathbf{n}=\mathbf{2 3})\end{array}$ & $\begin{array}{r}\text { Group B } \\
(\mathbf{n}=29)\end{array}$ & $\begin{array}{c}P \\
\text { value }\end{array}$ \\
\hline \multicolumn{4}{|l|}{ Interventricular septum } \\
\hline Preoperatively (mm) & $15.4 \pm 1.0$ & $15.6 \pm 1.0$ & .47 \\
\hline At 5-yr of follow-up (mm) & $14.0 \pm 1.4$ & $13.6 \pm 1.2$ & .27 \\
\hline Regression (mm) & $-1.5 \pm 0.9$ & $-2.0 \pm 0.8$ & .03 \\
\hline Percentage of regression & $-9.8 \pm 6.1$ & $-13.1 \pm 5.1$ & .03 \\
\hline \multicolumn{4}{|l|}{ Posterior wall } \\
\hline Preoperatively (mm) & $12.8 \pm 1.0$ & $12.7 \pm 1.3$ & .76 \\
\hline At 5-yr of follow-up (mm) & $11.5 \pm 1.6$ & $11.1 \pm 1.9$ & .42 \\
\hline Regression $(\mathrm{mm})$ & $-1.3 \pm 1.2$ & $-1.5 \pm 1.4$ & .58 \\
\hline Percentage of regression & $-8.3 \pm 6.9$ & $-12.1 \pm 10.5$ & .14 \\
\hline \multicolumn{4}{|l|}{ LVM } \\
\hline Preoperatively (g) & $207.6 \pm 30.1$ & $208.3 \pm 28.9$ & .93 \\
\hline At 5-yr of follow-up (g) & $198.3 \pm 30.5$ & $193.2 \pm 28.7$ & .56 \\
\hline Regression $(\mathrm{g})$ & $-9.3 \pm 3.3$ & $-15.0 \pm 7.8$ & .002 \\
\hline Percentage of regression & $-4.6 \pm 1.8$ & $-7.3 \pm 3.7$ & .002 \\
\hline \multicolumn{4}{|l|}{ LVM index } \\
\hline Preoperatively $\left(\mathrm{g} / \mathrm{m}^{2}\right)$ & $119.2 \pm 22.0$ & $121.6 \pm 20.8$ & .68 \\
\hline At 5-yr of follow-up $\left(\mathrm{g} / \mathrm{m}^{2}\right)$ & $113.8 \pm 21.8$ & $112.7 \pm 20.0$ & .85 \\
\hline Regression $\left(\mathrm{g} / \mathrm{m}^{2}\right)$ & $-5.3 \pm 1.9$ & $-8.8 \pm 4.2$ & .0005 \\
\hline Percentage of regression & $-4.6 \pm 1.8$ & $-7.3 \pm 3.7$ & .002 \\
\hline \multicolumn{4}{|l|}{$\mathrm{E} / \mathrm{E}^{\prime}$ ratio } \\
\hline Preoperatively & $15.3 \pm 3.0$ & $16.2 \pm 3.2$ & .33 \\
\hline At 5-yr of follow-up & $11.8 \pm 3.0$ & $12.1 \pm 3.3$ & .73 \\
\hline Regression & $-3.5 \pm 0.7$ & $-4.1 \pm 1.1$ & .02 \\
\hline \multicolumn{4}{|l|}{ LV ejection fraction $(\%)$} \\
\hline Preoperatively (\%) & $59.8 \pm 8.4$ & $58.9 \pm 6.8$ & .67 \\
\hline At 5 -yr of follow-up ( $\%)$ & $61.7 \pm 8.5$ & $62.5 \pm 6.3$ & .69 \\
\hline Regression $(\%)$ & $2.6 \pm 3.1$ & $3.5 \pm 2.8$ & .27 \\
\hline
\end{tabular}

Data presented as mean \pm standard deviation. $L V$, Left ventricular; $L V M$, LV mass.

to $12.1 \pm 3.3$ in group $\mathrm{B}$, with a regression ratio of $3.5 \pm$ 0.7 and $4.1 \pm 1.1$, respectively $(P=.02$; Table 2$)$.

\section{DISCUSSION}

The present study has shown that in patients with a hypertrophied septum, septal myectomy in association with AVR improves the regression of the LVM and diastolic function and does not increase the operative risk.

Asymmetric septal hypertrophy has been defined anatomically as disproportionate thickening of the anterior ventricular septum relative to the posterior LV free wall (usually a septal/free wall ratio $\geq 1: 3)^{2,9}$ From the available autopsy and echocardiographic data, about $10 \%$ of patients with hemodynamically significant AS show asymmetric thickening of the septum, which can be easily overlooked at AVR, resulting in a residual intraventricular gradient after successful AVR. ${ }^{12,13}$

No precise surgical guidelines are available for such cases. Most surgeons perform only AVR for 3 very important reasons. First, the patients are sent to them by the cardiologist with the diagnosis of AS. Second, they believe that by reducing the LV afterload with the replacement of the valve, 
the problem will be solved. Finally, they prefer to avoid any septal surgery to avoid complications, such as permanent atrioventricular block and septal perforation. Other surgeons perform AVR and septal myectomy but only in case of dynamic obstruction with systolic anterior motion of the mitral valve. ${ }^{9}$ Only a few recommend a more liberal use of septal myectomy in conjunction with AVR. ${ }^{5}$

These different surgical approaches result, in part, because the coexistence of asymmetric septal hypertrophy in patients with severe AS cannot always be precisely established preoperatively. Pressure measurements alone and ventriculography are not reliable indexes for detecting the severity of the obstruction. ${ }^{3,5}$ Sometimes, even transthoracic and transesophageal echocardiography can fail to properly detect septal hypertrophy. ${ }^{12}$ Therefore, the decision of whether to perform myectomy is made by the operating surgeon based on direct inspection (visual and manual) of the LV outflow tract after excision of the native aortic valve.

The rationale for performing myectomy at AVR is twofold: (1) to improve the long-term results; and (2) to eliminate the possibility that, once the aortic gradient has been relieved by AVR, a potential dynamic subaortic gradient would be "unmasked." The patient would have had operative relief of the fixed AS only to be confronted acutely with unanticipated subaortic stenosis with potentially deleterious clinical consequences in the early and late postoperative period. In a series of 11 patients with pure severe AS and without any anatomic signs of subvalvular obstruction, Bird and colleagues $^{14}$ found a large subvalvular gradient that worsened after AVR, thus, nullifying the results of an uneventful operation. Aurigemma and colleagues ${ }^{3}$ stressed that the hemodynamic changes after AVR can exacerbate a preexisting obstruction, with life-threatening consequences. Ayerbe and associates ${ }^{15}$ suggested prophylactic myectomy during AVR for patients with marked septal hypertrophy. Moreover, even in the absence of a postoperative gradient at rest, some amount of gradient can develop under stress after AVR and could affect the speed of LVM regression. ${ }^{4,16}$

In patients in whom myectomy was performed, we observed a regression of the LVM. Tasca and colleagues, ${ }^{4}$ in their retrospective analysis, found that the relative LV regression was significantly greater in patients who had undergone myectomy plus AVR than in patients who had undergone only AVR. Kayalar and colleagues, ${ }^{12}$ in their retrospective review of 47 patients who had undergone myectomy at AVR, found similar results at 1 year postoperatively.

In patients with AS, diastolic dysfunction is frequently observed. In such patients, LV hypertrophy is associated with alterations in LV relaxation, filling, and passive elastic properties, finally resulting in elevated end-diastolic pressures. Thus far, the E/A ratio has generally been used to evaluate the LV diastolic dysfunction. However, several limitations in using the $\mathrm{E} / \mathrm{A}$ ratio to asses $\mathrm{LV}$ diastolic function correctly have been detected, and the E/A ratio is no longer used to precisely assess LV diastolic function. ${ }^{17}$

The limitations of conventional mitral or pulmonary vein flow parameters in estimating the filling pressures of the left ventricle appear to have been partially overcome with the introduction of DTI. The early diastolic mitral annular velocity $\left(E^{\prime}\right)$ was found to be less load dependent than the conventional mitral flow variables, and the mitral $\mathrm{E} / \mathrm{E}^{\prime}$ ratio was suggested as an estimate of LV filling pressures. ${ }^{18}$ Moreover, the LV long-axis function reflects the position of the longitudinally oriented muscle fibers, adding precision to the LV evaluation. ${ }^{19}$ In our study, in the patients in whom myectomy was added to AVR, the $\mathrm{E} / \mathrm{E}^{\prime}$ ratio showed better diastolic normalization than that in patients who had undergone AVR alone.

Concomitant myectomy at AVR does not increase the operative risk. We did not have any patients with septal perforation or complete atrioventricular block requiring a permanent pacemaker. Also, reports from other centers have reported a negligible incidence of this complication. ${ }^{4,12}$

\section{Study Limitations}

One limitation is that the diastolic function was not evaluated with invasive catheter measurements, which is the reference standard. However, this invasive method is not suitable for widespread use and routine follow-up. The echocardiographic measurement of mitral $\mathrm{E} / \mathrm{E}^{\prime}$ ratio has been reported to be a precise estimate of LV filling pressures and allows routine noninvasive assessments.

Also, the mitral annular velocities can be significantly altered in the presence of coronary artery disease. LVM regression is a highly complex phenomenon involving hemodynamic and nonhemodynamic factors, including genetic and environmental ones. ${ }^{20,21}$

The small number of patients, the high degree of selectivity, the 2 different study periods with a different surgical strategy can also be considered limitations of our study; however, our inclusion criteria were strict, which may give significance to our study.

In conclusion, in patients undergoing AVR for severe AS, surgeons should inspect the LV outflow tract for possible concomitant myectomy at AVR. Concomitant septal myectomy is a simple procedure that does not increase the operative risk and gives good midterm results. However, only longer follow-up will be able clarify the definitive usefulness of this associated procedure.

\section{References}

1. Villari B, Vassalli G, Monrad ES, Chiariello M, Turina M, Hess OM. Normalization of diastolic dysfunction in aortic stenosis late after valve replacement. Circulation. 1995;91:2353-8.

2. Hess OM, Schneider J, Turina M, Carroll JD, Rothlin M, Krayenbuehl HP. Asymmetric septal hypertrophy in patients with aortic stenosis: an adaptive 
mechanism or a coexistence of hypertrophic cardiomyopathy? J Am Coll Cardiol. 1983;1:783-9.

3. Aurigemma G, Battista S, Orsinelli D, Sweeney A, Pape L, Cuénoud H. Abnormal left ventricular intracavitary flow acceleration in patients undergoing aortic valve replacement for aortic stenosis: a marker for high postoperative morbidity and mortality. Circulation. 1992;86:926-36.

4. Tasca G, Amaducci A, Parrella PV, Troise G, Dalla Tomba M, Magna Z, et al. Myectomy-myotomy associated with aortic valve replacement for aortic stenosis: effects on left ventricular mass regression. Ital Heart J. 2003;4:865-71.

5. Turina M. Asymmetric septal hypertrophy should be resected during aortic valve replacement. Z Kardiol. 1986;75(Suppl 2):198-200.

6. Giorgi D, Di Bello V, Talini E, Palagi C, Delle Donne MG, Nardi C, et al. Myocardial function in severe aortic stenosis before and after aortic valve replacement: a Doppler tissue imaging study. J Am Soc Echocardiogr. 2005;18:8-14.

7. Jin X, Zhang Z, Gibson D, Yacoub M, Pepper J. Effects of valve substitute on changes in left ventricular function and hypertrophy after aortic valve replacement. Ann Thorac Surg. 1996;62:683-90.

8. Stassano P, Di Tommaso L, Monaco M, Iorio F, Pepino P, Spampinato N, et al. Aortic valve replacement: a prospective randomized evaluation of mechanical versus biological valves in patients ages 55 to 70 years. J Am Coll Cardiol. 2009;54:1862-8.

9. Panza JA, Maron BJ. Valvular aortic stenosis and asymmetric septal hypertrophy: diagnostic considerations and clinical and therapeutic implications. Eur Heart J. 1988;9:71-6.

10. Bonow RO, Carabello BA, Kanu C, de Leon AC Jr, Faxon DP, Freed MD, et al. ACC/AHA 2006 guidelines for the management of patients with valvular heart disease: a report of the American College of Cardiology/American Heart Association Task Force on Practice Guidelines (Writing Committee to revise the 1998 Guidelines for the Management of Patients with Valvular Heart Disease): developed in collaboration with the Society of Cardiovascular Anesthesiologists: endorsed by the Society for Cardiovascular Angiography and Interventions and the Society of Thoracic Surgeons. Circulation. 2006;114: e84-231.
11. Devereux RB, Reichek N. Echocardiographic determination of left ventricular mass in man: anatomic validation of the method. Circulation. 1977;55:613-8.

12. Kayalar N, Schaff HV, Daly RC, Dearani JA, Park SJ. Concomitant septal myectomy at the time of aortic valve replacement for severe aortic stenosis. Ann Thorac Surg. 2010;89:459-64.

13. Shapiro LM, Howat AP, Crean PA, Westgate CJ. An echocardiographic study of localized subaortic hypertrophy. Eur Heart J. 1986;7:127-32.

14. Bird JJ, Murgo JP, Pasipoularides A. Fluid dynamics of aortic stenosis: subvalvular gradient without subvalvular obstruction. Circulation. 1982;66:835-40.

15. Ayerbe JL, Masip AE, Romero EA, Gonzales MM, Gonzales Alujas MM, Garcia del Castillo $\mathrm{H}$, et al. Predictive factors of abnormal dynamic intraventricular gradient after valve replacement in severe aortic stenosis. Rev Esp Cardiol. 2002;55 127-34.

16. Heinen MY, O'Sullivan C, Sutton GC, Gipson DG, Coats AJ. Stress-induced left ventricular outflow tract obstruction: a potential cause of dyspnea in the elderly. J Am Coll Cardiol. 1997;30:1301-7.

17. Paulus WJ, Tschöpe C, Sanderson JE, Rusconi C, Flachskampf FA Rademakers FE, et al. How to diagnose diastolic heart failure with normal left ventricular ejection fraction by the heart failure and echocardiography associations of the European Society of Cardiology. Eur Heart J. 2007;28:2539-50.

18. Ommen SR, Nishimura RA, Appleton CP, Miller FA, Oh JK, Redfield MM, et al Clinical utility of Doppler echocardiography and tissue Doppler imaging in the estimation of left ventricular filling pressures: a comparative simultaneous Doppler-catheterization study. Circulation. 2000;102:1788-94.

19. Bruch C, Stypmann J, Grude M, Gradaus R, Beithardt G, Wichter T. Tissue Doppler imaging in patients with moderate to severe aortic valve stenosis: clinical usefulness and diagnostic accuracy. Am Heart J. 2004;148:696-702.

20. Friddle CJ, Koga T, Rubin EM, Bristow J. Expression profiling reveals distinc sets of genes altered during induction and regression of cardiac hypertrophy. Proc Natl Acad Sci USA. 2000;97:6745-50.

21. de Simone G, Pasanisi F, Contaldo F. Link of nonhemodynamic factors to hemodynamic determinants of left ventricular hypertrophy. Hypertension. 2001;38:13-8. 